\title{
INTRODUCTION
}

\section{Integrated multi-trophic aquaculture (IMTA) in Sanggou Bay, China}

\author{
Jianguang Fang ${ }^{1,2, *}$, Jing Zhang ${ }^{3}$, Tian Xiao, ${ }^{4,5}$, Daji Huang ${ }^{6}$, Sumei Liu ${ }^{7,8}$ \\ ${ }^{1}$ Key Laboratory for Sustainable Utilization of Marine Fisheries Resources, Ministry of Agriculture, \\ Yellow Sea Fisheries Research Institute, 266071 Qingdao, PR China \\ ${ }^{2}$ Function Laboratory for Marine Fisheries Science and Food Production Processes, \\ Qingdao National Laboratory for Marine Science and Technology, 266237 Qingdao, PR China \\ ${ }^{3}$ State Key Laboratory of Estuarine and Coastal Research, East China Normal University, 200062 Shanghai, PR China \\ ${ }^{4}$ Key Laboratory of Marine Ecology \& Environmental Sciences, Institute of Oceanology, Chinese Academy of Sciences, \\ 266071 Qingdao, PR China \\ ${ }^{5}$ Laboratory for Marine Ecology and Environmental Science, \\ Qingdao National Laboratory for Marine Science and Technology, 266237 Qingdao, PR China \\ ${ }^{6}$ State Key Laboratory of Satellite Ocean Environment Dynamics, Second Institute of Oceanography, \\ State Oceanic Administration, 310012 Hangzhou, PR China \\ ${ }^{7}$ Key Laboratory of Marine Chemistry Theory and Technology, Ocean University of China/Qingdao Collaborative Innovation \\ Center of Marine Science and Technology, 266100 Qingdao, PR China \\ ${ }^{8}$ Qingdao National Laboratory for Marine Science and Technology, 266237 Qingdao, PR China
}

\begin{abstract}
Integrated multi-trophic aquaculture (IMTA) involves the farming of species from different trophic positions or nutritional levels in the same system. In China, IMTA has been practiced for many decades, with dozens of species farmed in close proximity to each other at the scale of whole coastal bays. Articles in this Theme Section present results from the MoST-China Project on 'Sustainability of Marine Ecosystem Production under Multi-stressors and Adaptive Management' (2011-2015). This project sought to understand the interactions between biogeochemical cycles and ecosystem function in the IMTA system of Sanggou Bay, China, which produces a total of $>240000 \mathrm{t}$ of seafood each year from $>30$ species in approximately $100 \mathrm{~km}^{2}$ of production space. Results include measurements of carbon, nitrogen flow and trophic relationships among cultured species; impacts of IMTA on benthic nutrient fluxes, reduced inorganic sulfur in sediments, distribution of dissolved inorganic selenium, and nutrient cycling; distribution and seasonal variation of picoplankton; and a model for kelp growth. Combined, the articles enable a complex understanding of the dynamics between IMTA and the environment in one of the most important coastal aquaculture production systems in the world.
\end{abstract}

KEY WORDS: Integrated multi-trophic aquaculture - Sanggou Bay - Biogenic elements · Ecological aquaculture

\section{Introduction}

In the 'Millennium Ecosystem Assessments' of the United Nations, climate, water, food, and health were identified as critical issues that need to be considered in adaptive ecosystem-based management plans to sustain human well-being (www.millenniumassess-

${ }^{*}$ Corresponding author: fangjg@ysfri.ac.cn ment.org). Marine aquaculture is increasingly seen as an alternative to fishing to provide a growing human population with high-quality protein. Aquaculture of high value species (e.g. fish in cages) relies on external food supplies and has a negative impact on water quality. Culture of seaweeds, which can reduce nutrient loadings to the environment from fish aquaculture, has

(C) The authors 2016. Open Access under Creative Commons by Attribution Licence. Use, distribution and reproduction are unrestricted. Authors and original publication must be credited. 
not been attractive in many countries as algal products typically have a low value. However, combining different species in aquaculture systems could provide more profit and have concomitant ecological benefits.

In 2011, the Ministry of Science and Technology (MoST) of China launched a $5 \mathrm{yr}$ research project on 'Sustainability of marine ecosystem production under multi-stressors and adaptive management' (MEcoPAM; MoST Grant No. 2011CB409800). The project addressed the following questions: (1) What are the impacts of multi-stressors on biogeochemical cycles in coastal ecosystems? (2) How do ecosystem functions in the hypoxic zone of the East China Sea respond to multi-stressors? (3) What adaptive strategies are possible for coastal aquaculture systems with multi-stressors?

Implementation of MEcoPAM's research strategy involved investigations off the Shandong Peninsula of North China, particularly in aquaculture areas of Sanggou Bay (Fig. 1). Field observations, microcosm experiments and modeling studies analyzed the combined effects of fish-catch, aquaculture, and enhancement activities on the structure and function of the coastal ecosystem, as well as responses of the ecosystem to multiple stressors. The goal was to develop adaptive management strategies for sustainable aquaculture systems.

\section{Aquaculture in Sanggou Bay}

Sanggou Bay is located on the eastern tip of Shandong Peninsula, China and is well known in the field of marine aquaculture, especially in integrated multitrophic aquaculture (IMTA). Overall, $>100 \mathrm{~km}^{2}$ of the
$163 \mathrm{~km}^{2}$ bay area are used for aquaculture, producing $>240000 \mathrm{t}$ of seafood per year (China Bay Records Compiling Committee 1991, Liu et al. 2014). More than 30 important aquaculture species, including kelp, scallops, oysters, abalone and sea cucumbers, are grown using various culturing methods such as long-lines, cages, bottom sowing and enhancement, pools in the intertidal zone, and tidal flat culture (Zhang et al. 2007).

The concept of IMTA was coined in 2004 and refers to the incorporation of species from different trophic positions or nutritional levels in the same system (Chopin \& Robinson 2004). However, IMTA has been successfully practiced in Sanggou Bay since the late 1980s (Fang et al. 1996). There are several IMTA modes in Sanggou Bay (Fig. 2), with benefits at the ecosystem level. For instance, co-culture of abalone and kelp provides combined benefits of a food source and waste reduction: abalone feed on kelp, and the kelp takes up nutrients released from the abalone (Tang et al. 2013). Co-culture of finfish, bivalves and kelp links organisms from different trophic levels so that the algae absorb nutrients released from finfish and bivalves, and bivalves feed on suspended fecal particles from the fish. Since kelp and Gracilaria lemaneiformis are cultured from December to May and from June to November, respectively, nutrients are absorbed by the algae throughout the year. These examples of multi-trophic culture maximize the utilization of space by aquaculture as they combine culture techniques in the pelagic and benthic zones. Implementation of IMTA in Sanggou Bay has improved economic benefits, maintained environmental quality, created new jobs, and led to culture technique innovations (Fang \& Zhang 2015).

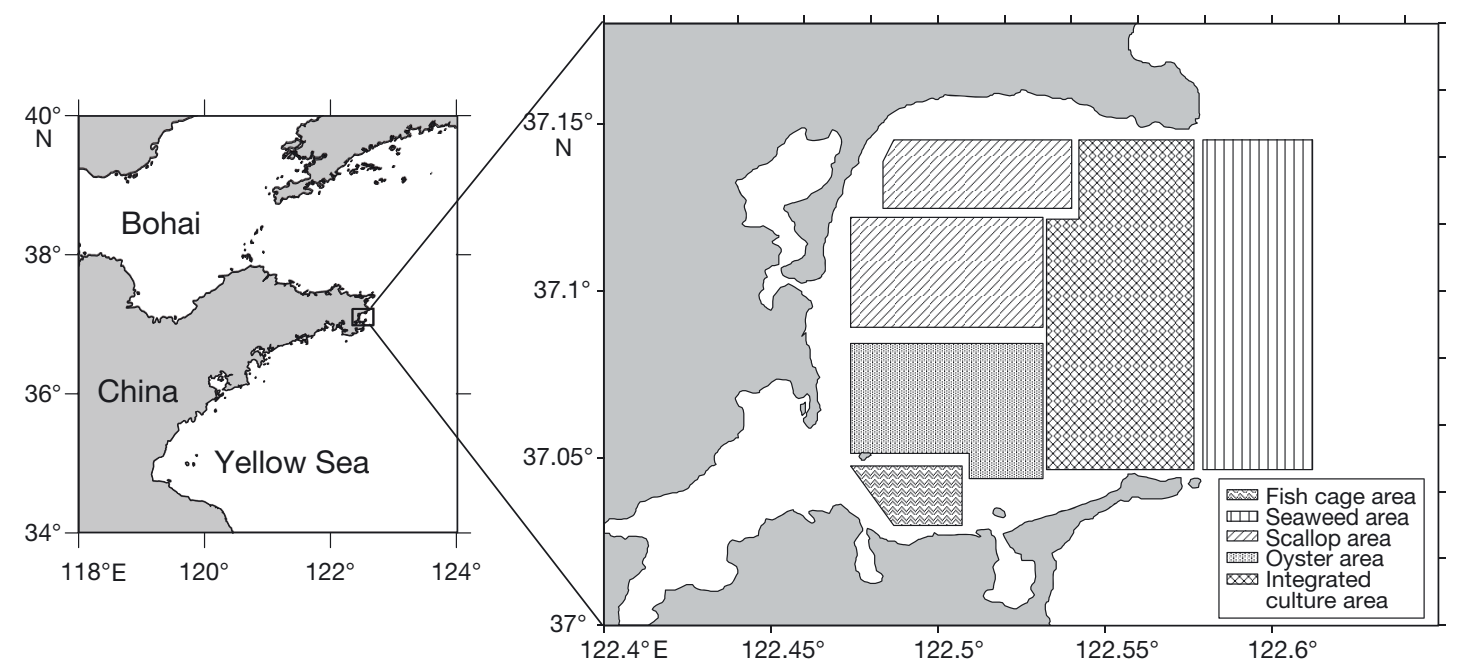

Fig. 1. Aquaculture areas in Sanggou Bay, Shandong Province, China 
A

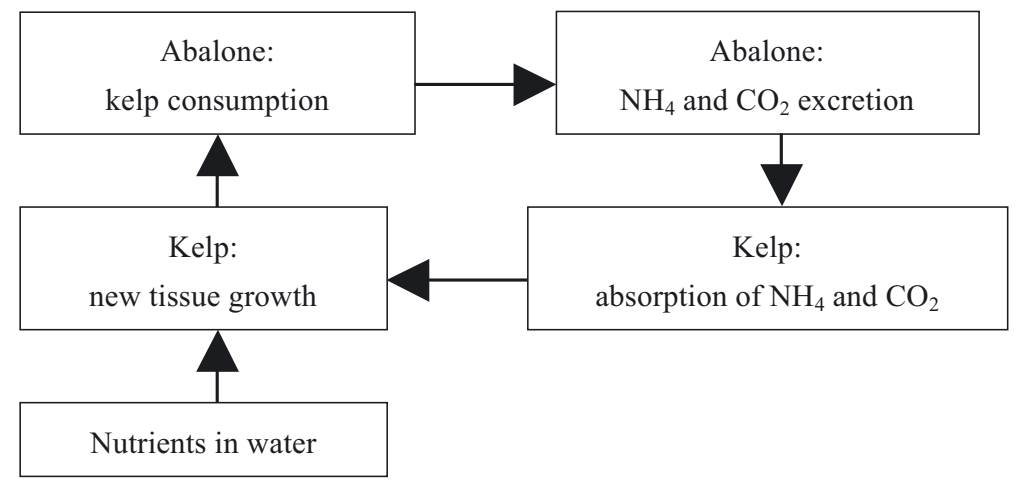

$\mathrm{B}$

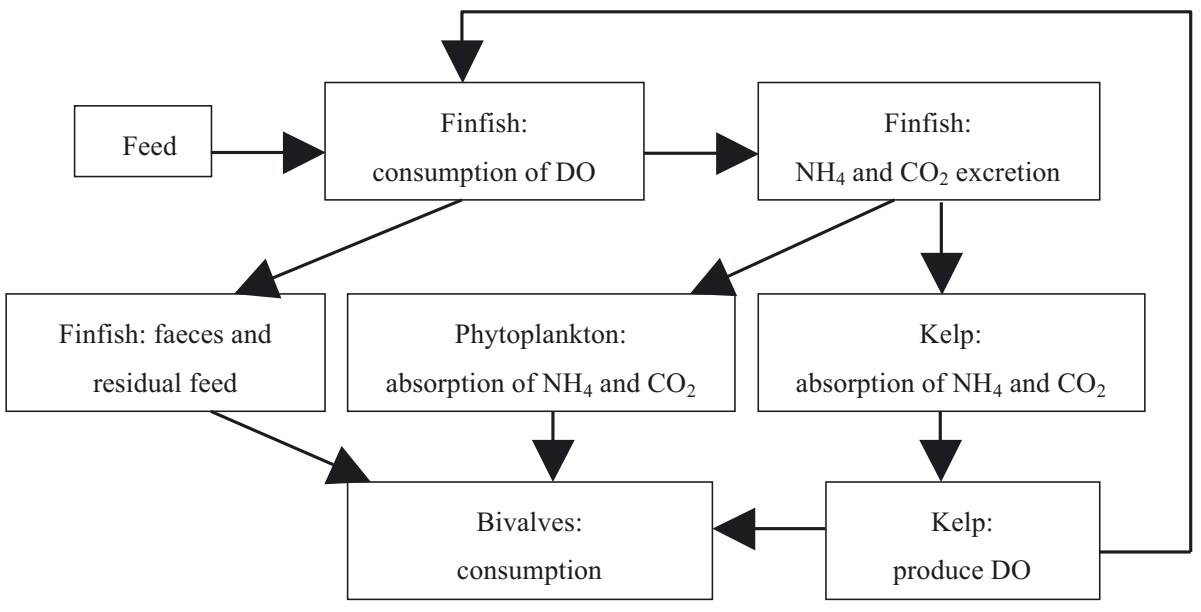

$\mathrm{C}$

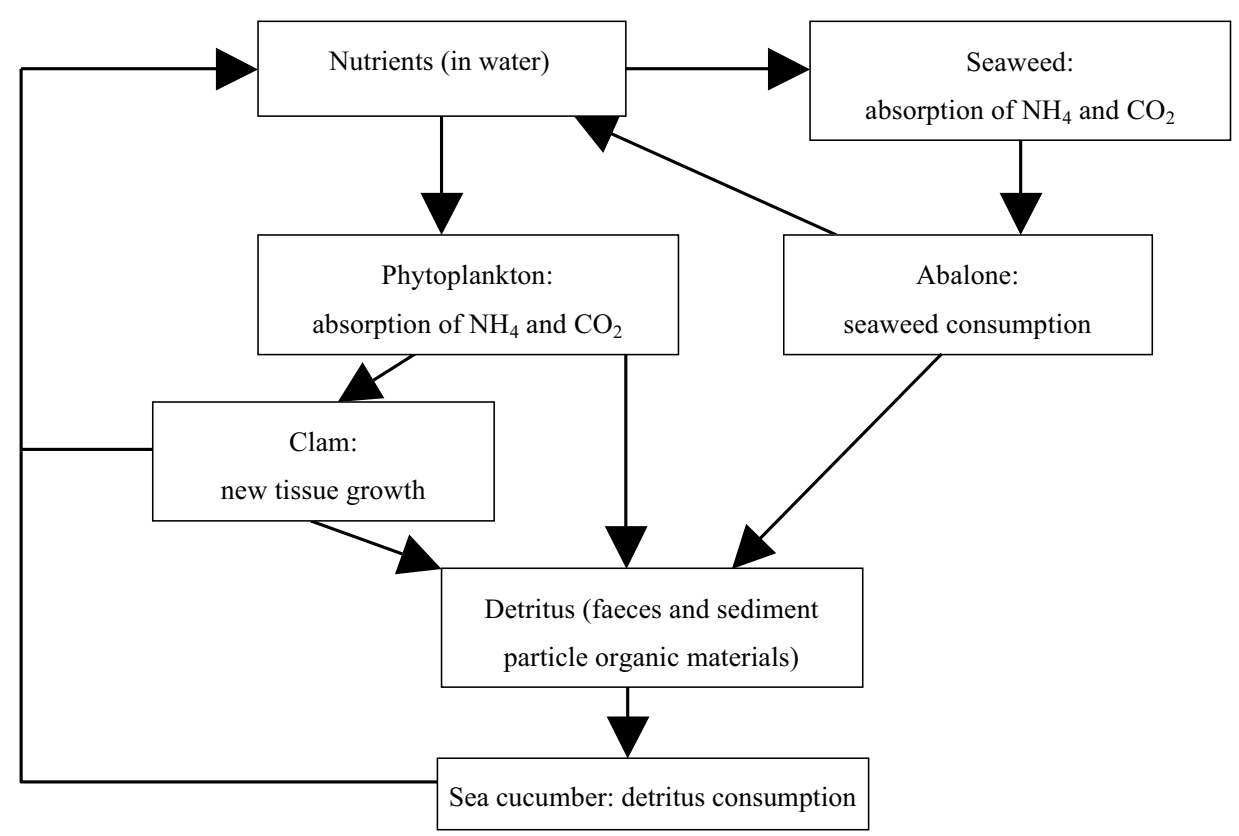

Fig. 2. Integrated multi-trophic aquaculture (IMTA) modes in Sanggou Bay, China, modified from Tang et al. (2013). (A) Longline culture of abalone and kelp, (B) long-line culture of finfish, bivalve and kelp, and (C) benthic culture of abalone, sea cucumber, clam and seaweed. DO: dissolved oxygen 
Moreover, the implementation of IMTA can increase the beneficial functions of an ecosystem. For instance, cage-culture of fish produces wastes in the form of uneaten feed, which induces the release of greenhouse gases into the atmosphere (i.e. a $\mathrm{CO}_{2}$ source). Fish farming in combination with seaweed culture can turn the system into a $\mathrm{CO}_{2}$ sink through photosynthesis and uptake of nutrients (Tang et al. 2011).

\section{Studies included in this Theme Section}

During the implementation of MEcoPAM in 2011-2015, Sanggou Bay has been a focal area to examine IMTA practices through interdisciplinary studies, combining physics, chemistry, biology and fisheries research. The papers included in this Theme Section reveal important connections between growth and production of cultured organisms and environmental quality, using approaches to understand cycling of biogenic elements and the function of the microbial loop.

Mahmood et al. (2016) measured stable isotopic signatures of organic carbon $\left(\delta^{13} \mathrm{C}\right)$ and total nitrogen $\left(\delta^{15} \mathrm{~N}\right)$ in suspended particulates and sediments to understand the sources of organic matter (OM), water quality and flow of organic carbon and nitrogen among IMTA species, as well as to evaluate the role of IMTA practices in accumulation and assimilation of OM during both wet and dry seasons.

Ning et al. (2016) measured benthic nutrient fluxes in Sanggou Bay in June and September 2012. In June, the early growth phase of cultured finfish and bivalves contributed little to biodeposition, and benthic nutrient fluxes tended to come from the sediment to the seawater and contributed to algal growth. In September, culture of finfish and bivalves resulted in high concentrations of nutrients in seawater and TOC in the sediment; $64 \%$ of the nitrogen and $25 \%$ of the phosphorus metabolized by bivalves were transferred from the seawater to the sediment.

Kang et al. (2016) compared reduced inorganic sulfur (including sediment acid-volatile sulfide, pyrite sulfur, elemental sulfur) and organic matter (OM) between a mariculture region of Sanggou Bay and a reference station to assess the influence of mariculture on sulfide accumulation and the benthic environment. They found that given the mariculture activities in Sanggou Bay, there was no potential threat of toxic sulfide to the benthic biomass.

Chang et al. (2016) investigated dissolved inorganic selenium concentrations in the water column, selenium content in biological species and sources of dissolved inorganic selenium entering Sanggou Bay. They discovered that the main source of dissolved inorganic selenium was water exchange with the Yellow Sea, whereas the most important sink was the intensive and widespread seaweed and bivalve aquaculture, which removed $53 \%$ of incoming selenium from bay waters.

Brown tide, caused by picoplankton, is a serious environmental problem in the world (Gastrich \& Wazniak 2002, Nuzzi \& Waters 2004, Zhang et al. 2012). Zhao et al. (2016) observed different patterns of picoplankton abundance and biomass, and analyzed the factors that affect the distribution and variation in abundance and biomass of picoplankton in aquaculture areas of Sanggou Bay.

Kelp Saccharina japonica is one of the most important mariculture species in China (Ministry of Agriculture 2015). Zhang et al. (2016) developed a dynamic growth model to evaluate environmental effects on kelp growth in Sanggou Bay. The model output provided useful information for improving the production and quality of kelp.

Aquaculture activities play an important role in nutrient cycling in Sanggou Bay (Li et al. 2016). Seasonal variations in nutrient concentrations were detected in the rivers entering the bay, particularly enrichment of dissolved inorganic nitrogen and silicate. The composition and distribution of nutrients were also affected by the species being cultured. The bivalve aquaculture was the major source of $\mathrm{PO}_{4}{ }^{3-}$, contributing $64 \%$ of total influx, and led to increased riverine fluxes of $\mathrm{PO}_{4}{ }^{3-}$. The substantial quantities of nitrogen and dissolved silicate accumulated in sediments or were transformed into other forms. Large quantities of DIN and $\mathrm{PO}_{4}{ }^{3-}$ were removed from the bay through harvesting of seaweeds and bivalves.

\section{Future directions}

Sustainable development in coastal ecosystems should be an important focus of modern aquaculture. Where aquaculture is to be embedded in coastal ecosystems, the inter-connections between production systems and the environment must be thoroughly understood. As a result, interest in exploring the potential for integrated aquaculture in brackish and marine ecosystems is growing (Soto 2009). The interactions among species in IMTA systems are complicated. Observational data and previous experience have shown the many positive aspects, both economic and environmental, of IMTA systems. Cur- 
rently, management of large-scale IMTA areas remains difficult, principally due to limited knowledge of how the separate components interact and function as a whole. The papers in this Theme Section provide detailed knowledge of how different IMTA species interact and affect the environment in regions that practice IMTA. Constructing and applying diagnostic models based on an understanding of the connections among species in IMTA systems and the surrounding environment can provide guidance to adaptively manage IMTA systems to ensure ongoing sustainability.

Acknowledgements. The guest editors thank all the contributors to this Theme Section and the reviewers for their valuable comments, and especially Dr. Tim Dempster for managing the Theme Section. Funding of Sanggou Bay studies came from the National Basic Research Program of China for the project 'Sustainability of Marine Ecosystem Production under Multi-stressors and Adaptive Management' (MoST Grant No. 2011CB409800). We also thank Prof. Qisheng Tang for advice and help in the implementation of IMTA, and Drs. Zeng Jie Jiang and Jing Hui Fang for preparing this Theme Section. We acknowledge the government and companies from Rongcheng for their help in facilitating our experiments in Sanggou Bay.

\section{LITERATURE CITED}

Chang Y, Zhang J, Qu J, Jiang Z, Zhang R (2016) Influence of mariculture on the distribution of dissolved inorganic selenium in Sanggou Bay, northern China. Aquacult Environ Interact 8:247-260

China Bay Records Compiling Committee (1991) Chinese bay records: the third section. Ocean Press, Beijing, p 377

Chopin T, Robinson S (2004) Defining the appropriate regulatory and policy framework for the development of integrated multi-trophic aquaculture practices: introduction to the workshop and positioning of the issues. Bull Aquacult Assoc Can 104:4-10

Fang J, Zhang J (2015) Types of integrated multi-trophic aquaculture practiced in China. World Aquacult 46: $26-30$

Fang J, Kuang S, Sun H, Li F, Zhang A, Wang X, Tang T (1996) Mariculture status and optimizing measurements for the culture of scallop Chlamys farreri and kelp Lami- naria japonica in Sanggou Bay. Mar Fish Res 17:95-102

Gastrich MD, Wazniak CE (2002) A brown tide bloom index based on the potential harmful effects of the brown tide alga, Aureococcus anophagefferens. Aquat Ecosyst Health Manage 5:435-441

Kang X, Liu S, Ning X (2016) Reduced inorganic sulfur in sediments of the mariculture region of Sanggou Bay, China. Aquacult Environ Interact 8:233-246

> Li R, Liu S, Zhang J, Jiang Z, Fang J (2016) Sources and export of nutrients associated with integrated multitrophic aquaculture in Sanggou Bay, China. Aquacult Environ Interact 8:285-309

Liu S, Yang Q, Yang S, Sun Y, Yang G (2014) The long-term records of carbon burial fluxes in sediment cores of culture zones from Sanggou Bay. Acta Oceanol Sin 36: 30-38

> Mahmood T, Fang J, Jiang Z, Zhang J (2016) Carbon and nitrogen flow, and trophic relationships, among the cultured species in an integrated multi-trophic aquaculture (IMTA) bay. Aquacult Environ Interact 8:207-219

Ministry of Agriculture (2015) China fishery statistic year book 2014. Chinese Agriculture Publishing House, Beijing

Ning Z, Liu S, Zhang G, Ning X and others (2016) Impacts of an integrated multi-trophic aquaculture system on benthic nutrient fluxes: a case study in Sanggou Bay, China. Aquacult Environ Interact 8:221-232

> Nuzzi R, Waters RM (2004) Long-term perspective on the dynamics of brown tide blooms in Long Island coastal bays. Harmful Algae 3:279-293

Soto D (ed) (2009) Integrated mariculture: a global review. FAO Fisheries and Aquaculture Technical Paper No. 529. FAO, Rome

Tang Q, Zhang J, Fang J (2011) Shellfish and seaweed mariculture increase atmospheric $\mathrm{CO}_{2}$ absorption by coastal ecosystems. Mar Ecol Prog Ser 424:97-104

Tang Q, Fang J, Zhang J, Jiang Z, Liu H (2013) Impacts of multiple stressors on coastal ocean ecosystems and integrated multi-trophic aquaculture. Prog Fish Sci 34:1-11

Zhang J, Wu W, Ren JS, Lin F (2016) A model for the growth of mariculture kelp Saccharina japonica in Sanggou Bay, China. Aquacult Environ Interact 8:273-283

Zhang Y, Zhang Y, Zhang W, Zhang J, Duan J, Li L, Lu S (2012) Size fraction of chlorophyll a during and after brown tide in Qinhuangdao coastal waters. Ecol Sci 31: 357-363

Zhang ZH, Lü JB, Ye SF, Zhu MY (2007) Values of marine ecosystem services in Sanggou Bay. Chin J Appl Ecol 18: 2540-2547

> Zhao L, Zhao Y, Xu J, Zhang W and others (2016) Distribution and seasonal variation of picoplankton in Sanggou Bay, China. Aquacult Environ Interact 8:261-271 